\title{
INHERITED PROTHROMBOTIC RISK FACTORS IN MIGRAINE, STROKE, OR TRANSIENT ISCHEMIC ATTACK
}

The prevalence and association of inherited prothrombotic risk factors in children with established diagnoses of stroke, transient ischemic attack, or migraine were studied at Zagreb University School of Medicine, Croatia. Genotypic analyses were performed for factor V G1691A, factor II G2010A, MTHFR C677T, and 4 common platelet glycoprotein polymorphisms. Only factor $\mathrm{V}$ was significantly associated with increased risk for arterial ischemic stroke (AIS) in childhood and perinatal arterial ischemic stroke (PAS). Heterozygosity for factor V G1691A was associated with a 7-fold increased risk for AIS, PAS, and transient ischemic attack (TIA). Carriers of human platelet alloantigens had an increased risk of TIA. Human platelet alloantigen-2b allele was associated with a 2.23 -fold increased risk for migraine, whereas factors $\mathrm{V}$ and II were not implicated. A trend toward an increased risk for migraine in children homozygous for MTHFR C677T, especially migraine with aura, was not statistically significant. (Herak DC, Antolic MR, Krleza JL, et al. Inherited prothrombotic risk factors in children with stroke, transient ischemic attack, or migraine. Pediatrics April 2009;123:e653-e660). (Respond: Renata Zadro PhD, Clinical Hospital Center, Kispaticeva 12, Zagreb 10000, Croatia. E-mail: rzadro@mef.hr).

COMMENT. Factor V G1691A is important in susceptibility to arterial ischemic stroke in childhood and the perinatal period, and transient ischemic attacks. Platelet glycoprotein polymorphisms may increase the risk of TIA and migraine.

\section{INFECTIOUS DISORDERS}

\section{COMPARISON OF SENSITIVITY OF SERUM AND CSF SAMPLES IN IMMUNODIAGNOSIS OF NEUROCYSTICERCOSIS}

Paired serum and CSF samples were obtained from 91 patients with neurocysticercosis (NCC) for detection of Taenia solium (TS) antibodies and antigens, in a study at centers in Lima, Peru, Belgium, and the USA. TS antibodies were detected using an enzyme-linked immunotransfer blot (EITB) assay, and antigens, using a monoclonal antibody-based enzyme-linked immunosorbent assay (ELISA). NCC was intraparenchymal in 48 and extraparenchymal in 43 patients. For the intraparenchymal NCC group, the EITB antibody assay yielded more true positive results on serum samples, whereas the ELISA antigen assay yielded slightly more positive results for CSF samples (differences not significant). Patients with calcified NCC were antibody positive and antigen negative. For extraparencymal disease, all samples were antibody positive, and all but 2 were antigen positive, mostly with high antigen levels. (Rodriguez S, Dorny P, Tsang VCW, et al, for the Cysticercosis Working Group in Peru. Detection of Taenia solium antigens and anti-T. solium antibodies in paired serum and cerebrospinal fluid samples from patients with intraparenchymal or extraparenchymal neurocysticercosis. J Infect Dis May 2009;199:13451352) (Respond or reprints: Dr Hector H Garcia, Dept of Microbiology, Universidad Peruana Cayetano Heredia, Av H Delgado 430, SMP, Lima 31, Peru. E-mail: hgarcia@jhsph.edu). 